\title{
Sensitivity of an atmospheric general circulation model to the parameterization of leads in sea ice
}

\author{
Gregory M. Flato, David Ramsden \\ Canadian Centre for Climate Modelling and Analysis, Atmospheric Environment Service, University of Victoria, \\ P.O. Box 1700, Victoria, British Columbia, V8W 212, Canada
}

\begin{abstract}
Open-water leads in sea ice dominate the exchange of heat between the ocean and atmosphere in ice-covered regions, and so must be included in climate models. A parameterization of leads used in one such model is compared to observations and the results of a detailed Arctic sea-ice model. Such comparisons, however, are hampered by the errors in observed lead fraction, but the parameterization appears to compare better in winter than in summer. Simulations with an atmospheric general circulation model (AGCM), using prescribed sea-surface temperatures and ice extent, are used to illustrate the effect of parameterized lead fraction on atmospheric climate, and so provide some insight into the importance of improved lead-fraction parameterizations and observations. The effect of leads in the AGCM is largest in Northern Hemisphere winter, with zonal mean surface-air temperatures over ice increasing by up to $5 \mathrm{~K}$ when lead fraction is increased from $1 \%$ to near $5 \%$. The effect of leads on sensible heat loss in winter is more important than the effect on radiative heat gain in summer. No significant effect on sealevel pressure, and hence on atmospheric circulation, is found, however. Indirect effects, due to feedbacks between the atmosphere and ice thickness and extent, were not included in these simulations, but could amplify the response.
\end{abstract}

\section{INTRODUGTION}

Sea ice affects the climate at high latitudes by insulating the ocean from the atmosphere, and by increasing the surface albedo. Leads are narrow veins of open water and thin ice within the polar ice pack that occupy only a small fraction of the ice-covered area, but that dominate the turbulent heat exchange in winter by exposing relatively warm ocean water to the cold atmosphere (e.g. Maykut, 1978). In this paper the term "leads" is used rather loosely to mean any open water within the ice pack. In winter, this open water takes part in a negative feedback whereby high heat loss quickly forms ice that covers the open leads. On the other hand, in summer the reduction of surface albedo by leads and surface melt ponds enhances absorption of solar radiation, accelerates ice melt, and hence contributes to the positive ice-albedo feedback. These feedbacks are largely responsible for the enhanced greenhouse-gas warming at high latitudes predicted by global climate models, and so it is important to represent them accurately (e.g. Rind and others, 1995). The parameterization of sea-ice processes in global climate models is improving with the implementation of sea-ice dynamic schemes and prognostic equations for lead fraction, but improvements are hampered by uncertainty in the actual lead fraction. Errors in passive-microwave satellite observations of ice concentration (the fraction of area covered by ice) arise from variations in surface temperature and emissivity, atmospheric effects, and the presence of surface melt ponds in summer. These errors are largest during the summer melt period, and range from roughly $2 \%$ to $7 \%$ in the Arctic and $3 \%$ to $10 \%$ in the Antarctic (Cavalieri, 1992). This translates into nearly 100\% errors in the observed open-water fraction. The present work illustrates the sensitivity of an atmospheric general circulation model (AGCM) to variations in lead fraction of this magnitude.

Much of the previous work relating to this topic addressed the effect of variations in ice-edge position on atmospheric climate in an AGCM where the sea-surface temperature (SST) and sea-ice amount are specified. Extreme examples are the complete ice-removal experiments of Royer and others (1990 and earlier references therein) while less extreme cases have been studied by Herman and Johnson (1978), Mitchell and Senior (1989), and Raymo and others (1990). Typical findings are that ice-edge retreat causes local atmospheric warming of up to $20 \mathrm{~K}$ and a lowering of surface pressure by as much as $10 \mathrm{mb}$, but that away from the ice anomaly the effects are weak.

The role of leads within the ice cover has received less attention, but has been examined in an energy-balance model by Ledley (1988), in an AGCM by Simmonds and Budd (1991), and in a very low-resolution global coupled atmosphere slab-ocean model by Vavrus (1995). Of these, both Ledley (1988) and Vavrus (1995) consider the sensitivity of a coupled climate model (including ice extent) to varying lead fraction. Although such coupled models provide an estimate of the coupled system's overall sensitivity to leads, this sensitivity depends on the accuracy of the representation of all components in the coupled system. In the present work we follow Simmonds and Budd (1991) and focus only on the direct impact of leads on atmospheric climate, realizing that this may be moderated or enhanced by other feedbacks in the coupled system.

The study of Simmonds and Budd (1991) focused on the 
Antarctic ice cover and consisted of perpetual July simulations with lead fractions varying from $5 \%$ to $100 \%$. They found that the surface-air temperature over the Antarctic sea ice increased by $2.0 \mathrm{~K}$ when the lead fraction was increased from $0 \%$ to $5 \%$, by $12.5 \mathrm{~K}$ when lead fraction was increased to $50 \%$, and by $17.5 \mathrm{~K}$ when the ice cover was removed. They also found increases in sensible heat flux of $12-103 \mathrm{~W} \mathrm{~m}^{2}$, and a decrease in surface pressure of 0.2 $3.3 \mathrm{mb}$ for the same range of lead fraction. Their results for $0 \%$ and $5 \%$ lead fraction are the most relevant in the present context, and these will be referred to later.

In the present work a somewhat higher-resolution model than that of Simmonds and Budd (1991) was used, and simulations were conducted that included the full annual cycle. As described in the following section, some mean March and September atmospheric surface quantities were compared across the entire globe (representing the time of minimum and maximum ice extent in each hemisphere).

\section{MODEL DESGRIPTION, LEAD PARAMETERIZA- TION AND EXPERIMENTAL DESIGN}

The model used in the present study is a version of the Canadian Climate Centre AGCM, called GCMII, described by McFarlane and others (1992); this was also used in the equilibrium climate-change experiments by Boer and others (1992). Briefly the model has T32/L10 resolution and interactive cloud and land-surface schemes. Although the original model included an interactive mixed-layer ocean and thermodynamic sea ice, the present version uses a specified climatological annual cycle of sea-surface temperature and ice amount obtained from the Atmospheric Model Intercomparison Project (AMIP) dataset (Gates, 1992). The AMIP dataset does not include ice thickness, but only indicates its presence or absence, so ice thickness was specified from climatological estimates based on mean surface temperature. This version of the model has been used in a variety of AMIP simulations (e.g. Zwiers, in press). Since the model and its equilibrium climate is described in detail in McFarlane and others (1992), only that aspect of the model formulation that is pertinent to the present set of experiments, namely the parameterization of leads, is mentioned here.

Leads are parameterized in terms of ice thickness according to the scheme presented in McFarlane and others (1992), namely,

$$
\varepsilon_{\mathrm{L}}=\min \left[\left(h_{\min } / h\right)^{n}, 1\right]
$$

where $\varepsilon_{\mathrm{L}}$ is the lead fraction (one minus the concentration), $h$ is the ice thickness, $h_{\min }=0.05 \mathrm{~m}$, and $n$ is a dimensionless parameter taken to be 1.25 by McFarlane and others (1992). According to this parameterization, thin ice $(<0.05 \mathrm{~m})$ is treated in the same way as open water. Simultaneous observations of lead fraction and mean thickness are not available to verify this parameterization directly; however the recent Arctic ice model results of Flato and Hibler (1995) can be used to provide some indication of its suitability. Figure 1 shows a scatter plot of the March and September lead fraction vs thickness obtained from the model developed by Flato and Hibler (1995)(there is one dot for each model gridpoint for each of the seven years of their "standard" simulation). Also shown in this figure is equation (1), with the standard value of $n=1.25$, and also with a "low-lead" value of $n=1.75$ and a "high-lead" value a

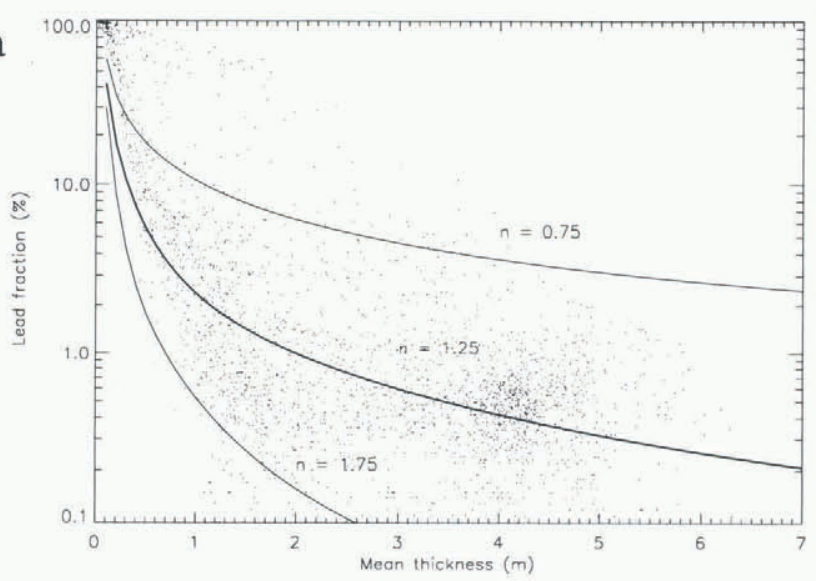

b

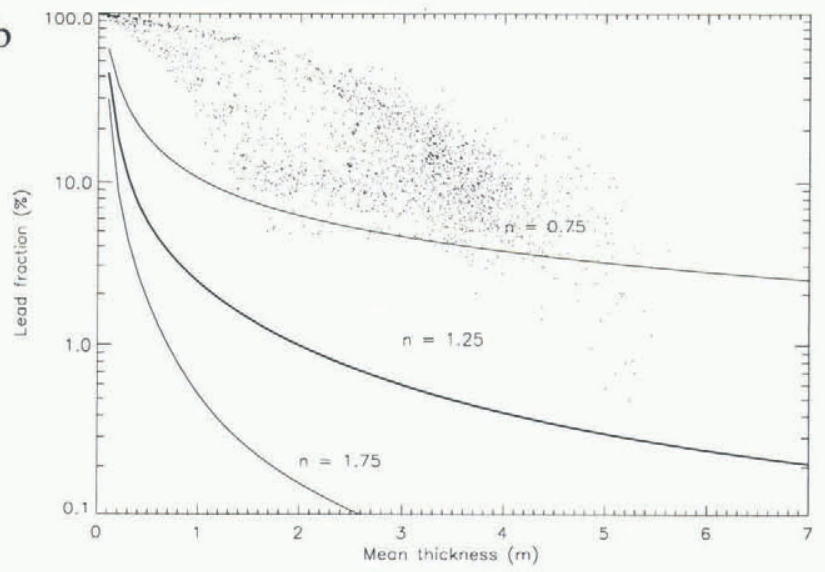

Fig. 1. Scatter plot of lead fraction vs mean thickness obtained from the model of Flato and Hibler (1995) for the Arctic in March (a) and September (b). Superimposed are three curves representing equation (1) with various values of $n$. The heavy line is the standard case with $n=1.25$.

of $n=0.75$. In winter, the standard version of the parameterization reflects the trend of decreasing lead fraction with increasing thickness reasonably well; but in summer, the parameterized lead fraction is too low by roughly an order of magnitude. This comparison highlights an immediate shortcoming of the parameterization, namely that the seasonal cycle of lead fraction is not well reproduced. Nevertheless, the range of $n$ shown in the figure, corresponding to lead fractions of $0.1 \%, 1 \%$ and $5 \%$ for a typical ice thickness of $3 \mathrm{~m}$, does span the range of modelled winter values and is similar to the range of uncertainty in observed lead fraction.

An alternative comparison that allows the use of mean monthly passive-microwave estimates of ice concentration (Gloersen and others, 1992) is provided by Figure 2. This figure compares the distribution functions of observed and parameterized lead fraction for March and September in both hemispheres. In the Northern Hemisphere, the model results of Flato and Hibler (1995) are also shown. (Note that errors in the specified climatological ice-thickness fields translate directly into errors in the parameterized lead fraction.) As was indicated by the comparison in Figure 1, the standard parameterization in winter agrees well with the results of Flato and Hibler's (1995) model, but in this comparison both seem to underestimate the observed amount of ice with high-lead fractions. In summer, the unrealistically low-lead fraction produced by the standard version of (1) is apparent, whereas the high-lead case provides some- 
a

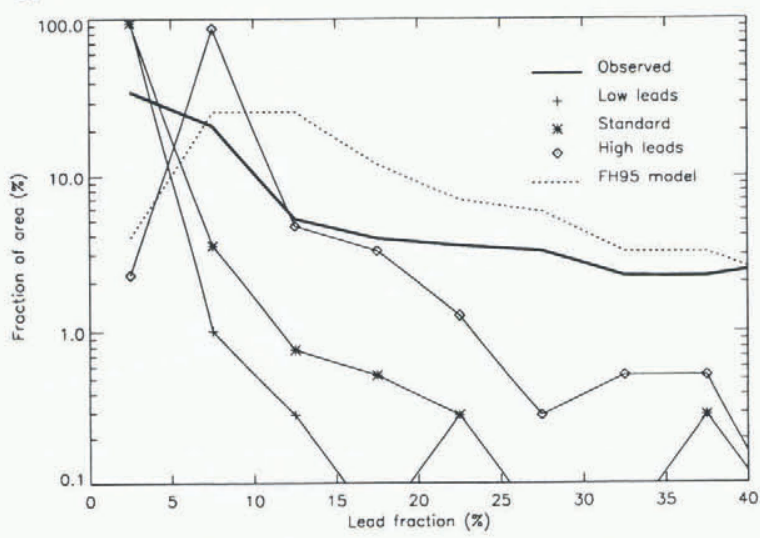

C

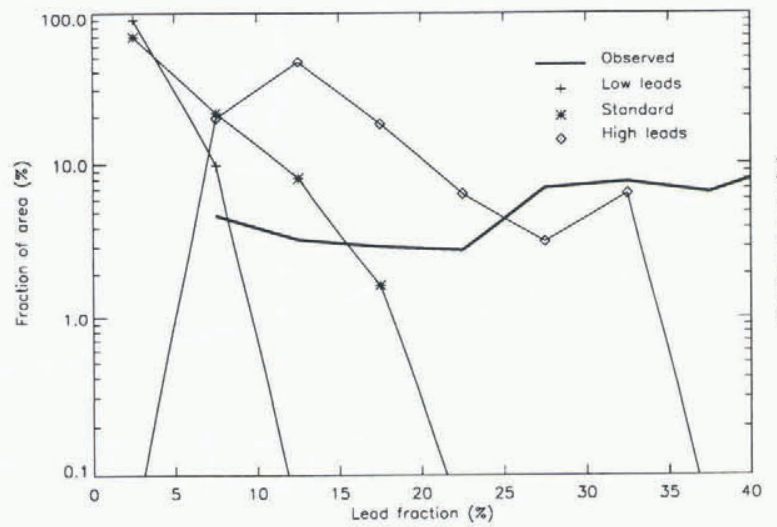

b

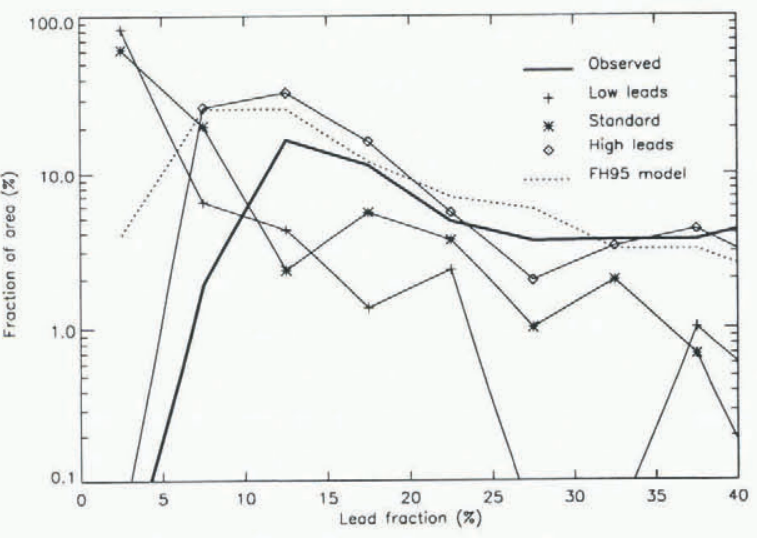

d

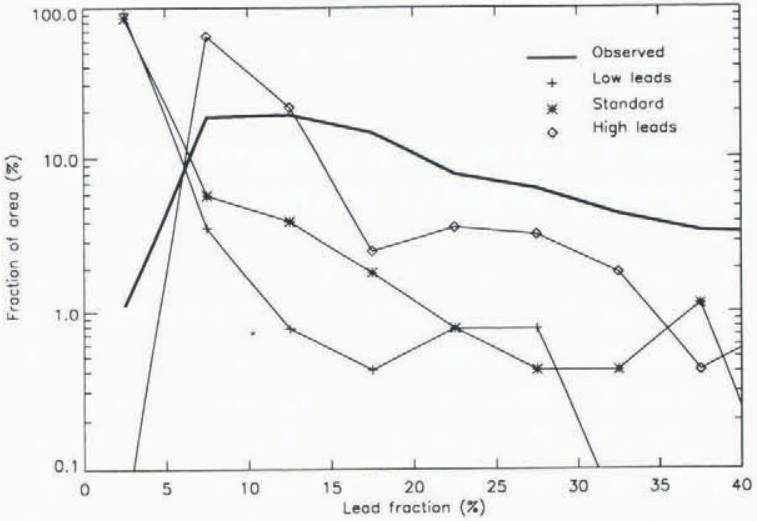

Fig. 2. Distribution functions of lead fraction (i.e. the fraction of ice-covered area occupied by ice with a given lead fraction). The solid line is from the passive-microwave observations summarized by Gloersen and others (1992); the dashed line (FH95) is from the Arctic model of Flato and Hibler (1995); the symbols are the parameterized lead fractions used in the three AGCM simulations described. (a) Northern Hemisphere in March. (b) Northern Hemisphere in September. (c) Southern Hemisphere in March. (d) Southern Hemisphere in September.

what better agreement. In the Southern Hemisphere, the parameterization does not appear to be especially good in either season, although the high-lead case does agree better with observations than the standard case. It is not clear how the errors inherent in the passive-microwave observations might distort the shape of the curves in Figure 2.

Setting aside the question of how to best parameterize leads in an AGCM, we may still inquire as to the effect of such parameterizations on the modelled climate. The programme is to compare three multi-year simulations performed with the AGCM: a 40 year control run using the standard parameterization; a 10 year "low-lead" experiment with $n=1.75$, and a 10 year "high-lead" experiment with $n=0.75$. Aside from the change in $n$, all other model parameters and boundary conditions (sea-surface temperature, ice thickness, and solar constant) are kept the same. In particular, because the ice extent and thickness is specified, the only aspect of the ice cover explicitly modified is the lead fraction. Note that because the surface albedo depends on surface temperature and snow amount, both of which evolve freely in the model, there is the potential for some feedback to the direct effect of changing lead fraction. Differences between long-term means of these three runs are therefore a result of the overall response of the atmosphere, ice and land surfaces to the change in lead fraction, with an additional contribution due to internal variability. The effect of variability has been reduced by averaging over multi-year model integrations.

\section{EXPERIMENTAL RESULTS}

To illustrate the effects of lead fraction, differences are plotted between the "high-lead" and standard case, and between the "low-lead" and standard case. Figures 3 and 4 show these differences for March and September surface ( $2 \mathrm{~m}$ height) air temperature, while Figures 5 and 6 show the differences for mean sea-level pressure.

The high-lead case has a more dramatic effect on air temperature than the low-lead case, indicating that, in the standard case, the effect of leads is relatively minor (i.e. further reduction of the lead fraction has little impact). Zonal mean temperature in the Arctic in March is increased by about $5 \mathrm{~K}$ in the high-lead case, and decreased by only about $1 \mathrm{~K}$ in the low-lead case. In the Antarctic in September the effect is weaker, with an increase of about $1 \mathrm{~K}$ in the high-lead case and negligible change in the low-lead case. South of $60^{\circ} \mathrm{N}$ and north of $60^{\circ} \mathrm{S}$, there is no perceptible effect in either case. The change in lead fraction clearly has the largest effect in the winter hemisphere, a result of the importance of leads in ocean-sensible heat loss in winter. Although not shown, the net surface-energy flux in the high-lead case indicates enhanced ocean heat loss by about $20 \mathrm{~W} \mathrm{~m}^{-2}$ in March, but only about $10 \mathrm{~W} \mathrm{~m}^{-2}$ more heat gain in September. This supports the result of Vavrus (1995), who found that increased lead fraction resulted in more ice growth and hence a thicker ice cover.

Changes in surface pressure, shown in Figure 5, are rela- 
a

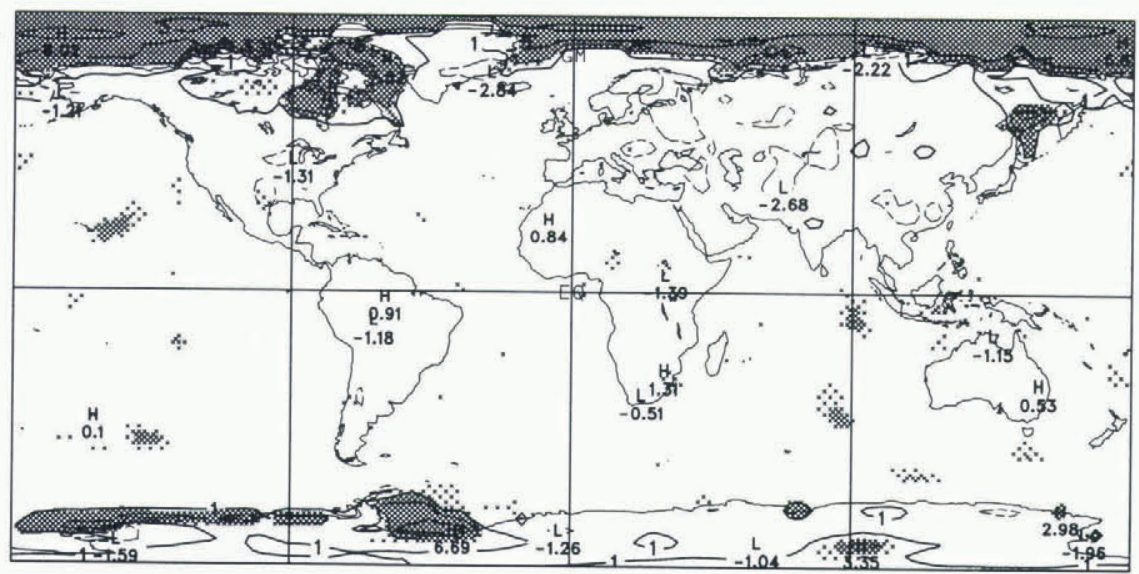

b

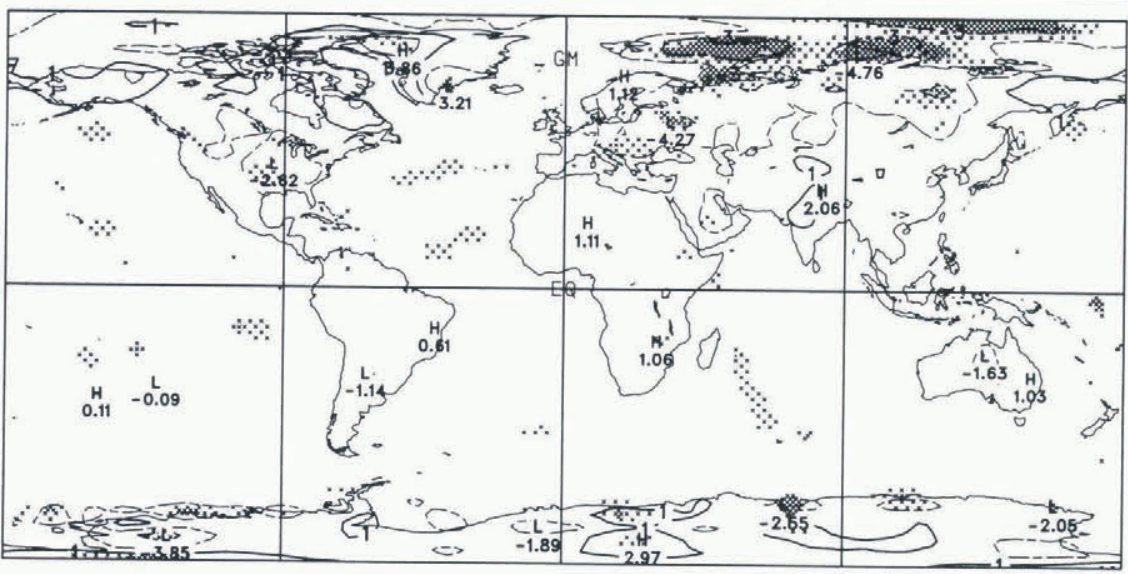

Fig. 3. March surface-air temperature difference between the high-lead and standard cases ( $a$ ), and the low-lead and standard cases ( $b$ ). The contour interval is $2 \mathrm{~K}$; light shading indicates that the difference is significant at the $10 \%$ level, and dark shading indicates differences significant at the $5 \%$ level.

a

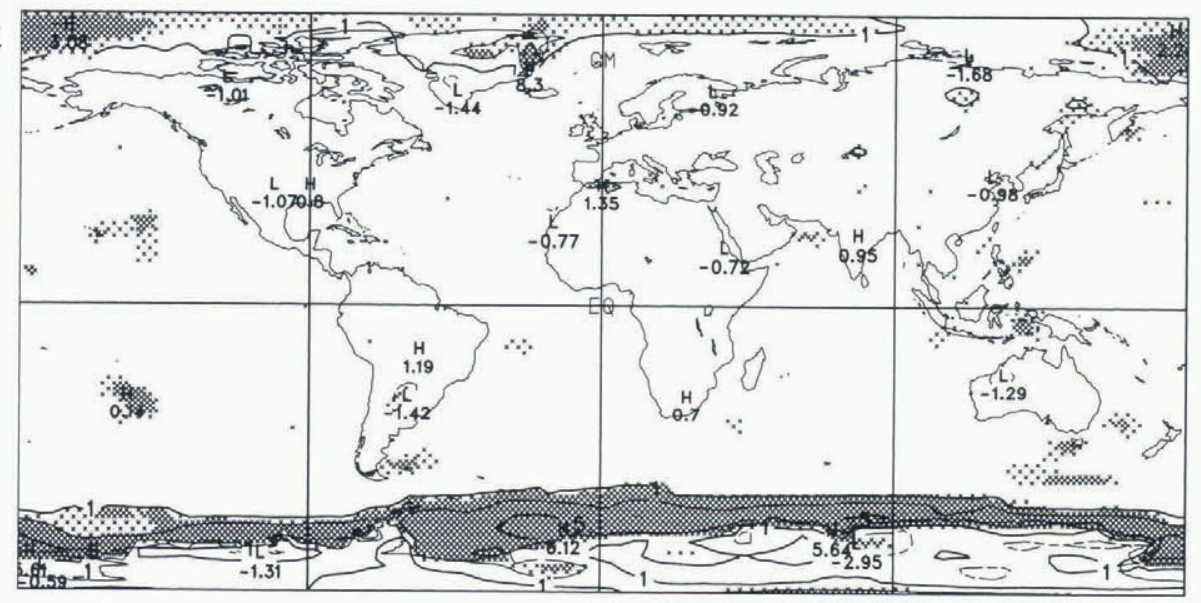

b

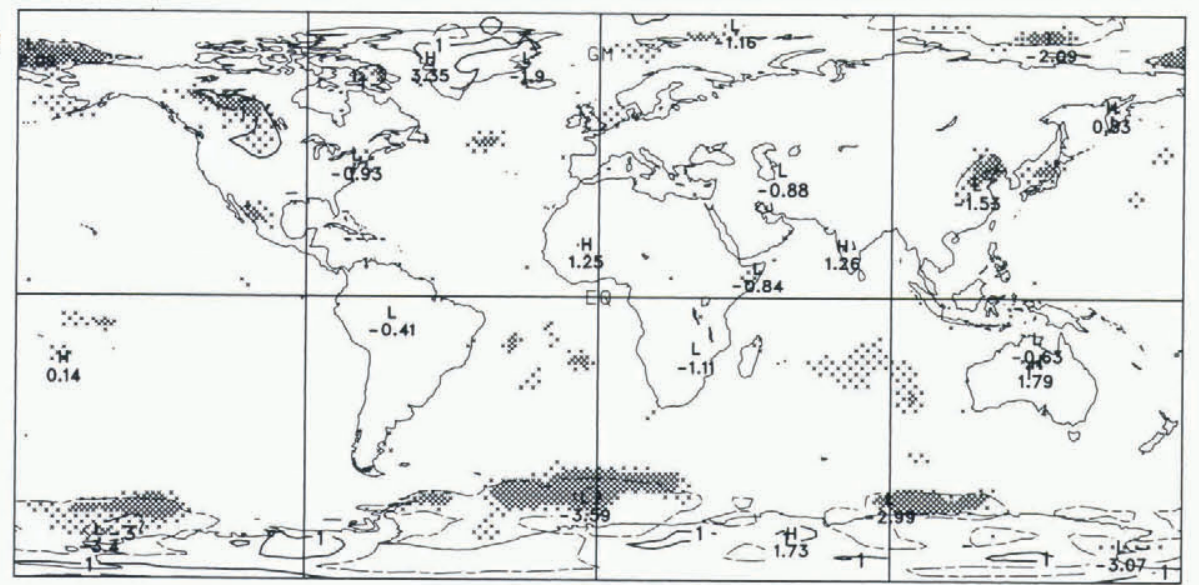

Fig. 4. September surface-air temperature difference between the high-lead and standard cases ( a), and the low-lead and standard cases (b). The contour interval is $2 \mathrm{~K}$; light shading indicates that the difference is significant at the $10 \%$ level, and dark shading indicates differences significant at the $5 \%$ level. 

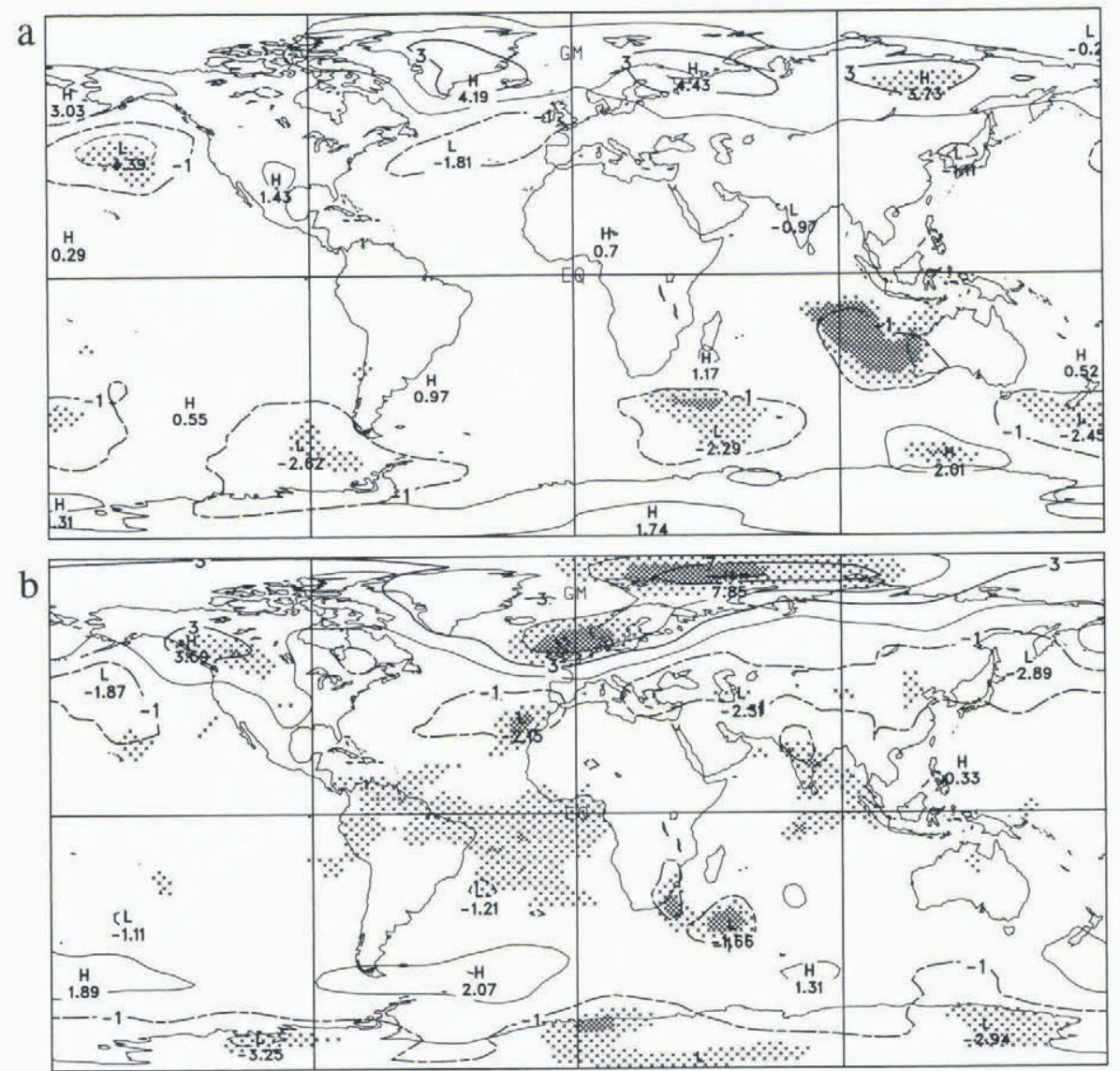

Fig. 5. March mean sea-level pressure difference between the high-lead and standard cases (a), and the low-lead and standard cases (b). The contour interval is $2 \mathrm{mb}$; light shading indicates that the difference is significant at the $10 \%$ level, and dark shading indicates differences significant at the $5 \%$ level.
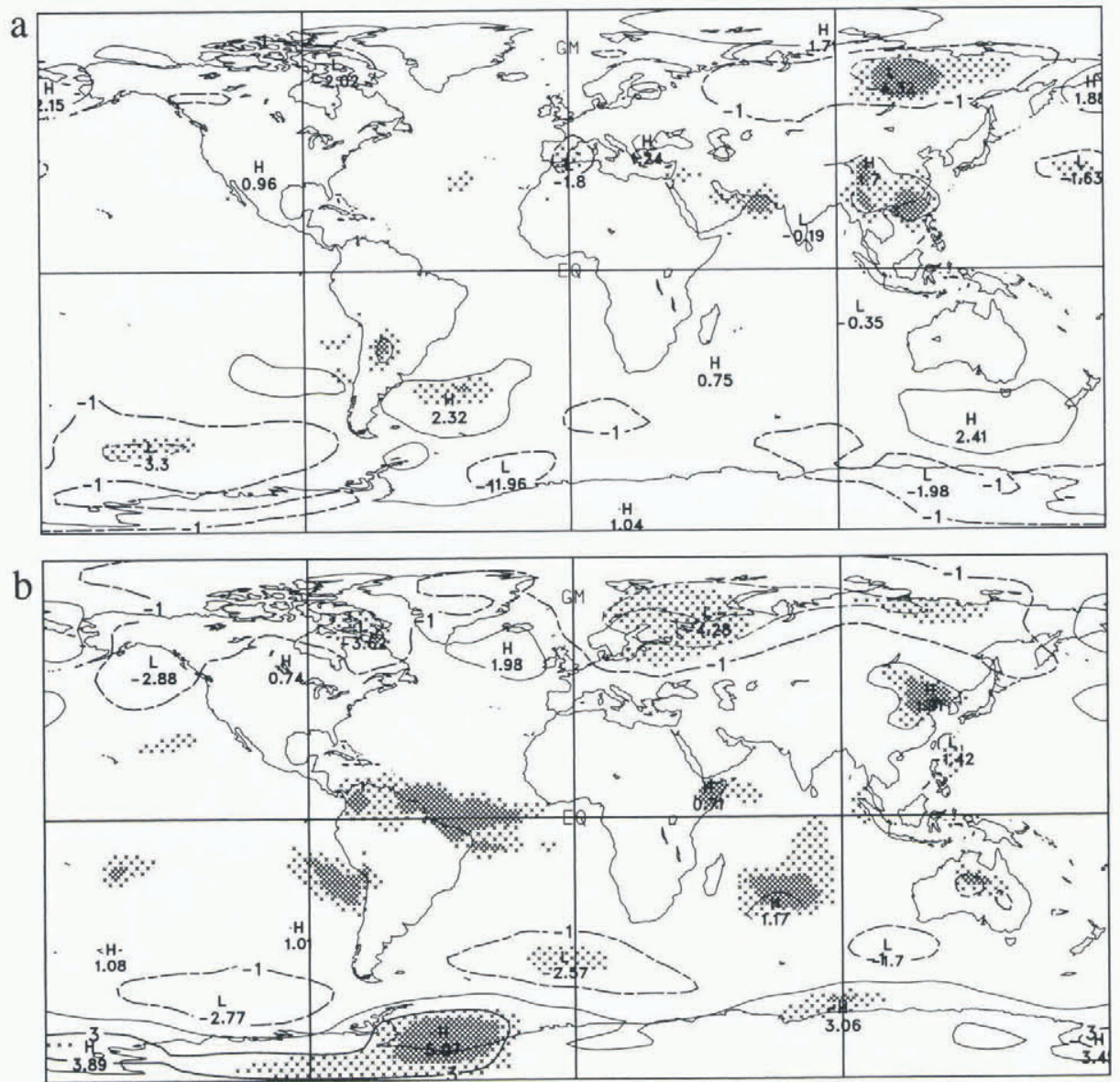

Fig. 6. September mean sea-level pressure difference between the high-lead and standard cases (a), and the low-lead and standard cases ( $b$ ). The contour interval is $2 \mathrm{mb}$; light shading indicates that the difference is significant at the $10 \%$ level, and dark shading indicates differences significant at the $5 \%$ level. 
tively modest compared to changes in air temperature, and in fact are generally insignificant (at the 5\% level, about $5 \%$ of the area shows as significant purely by chance). This indicates that, in spite of the local changes in surface heat budget and air temperature, changes in lead fraction of the magnitude considered here do not significantly alter the climatological atmospheric circulation patterns. Precipitation patterns were likewise found to be unchanged.

\section{DISCUSSION AND CONCLUSIONS}

Sea ice, and the open-water leads within it, are important features of the climate system, and more sophisticated seaice dynamic and thermodynamic schemes are being incorporated in climate models. However, simple lead parameterizations have been widely used and will remain useful in many idealized climate simulations. It is therefore of interest to examine the fidelity of such a parameterization, and to investigate the sensitivity of the climate system to inaccuracies in the parameters and uncertainty in the actual lead fraction that such schemes attempt to reproduce. Comparison of one such lead-fraction parameterization, (1), with the model results of Flato and Hibler (1995) and observed lead fraction, indicate that it performs best in the Northern Hemisphere winter, with some shortcomings that might be improved by allowing the parameter $n$ to vary with season.

Climate simulations with an AGCM illustrate the direct effect of changes in lead fraction on atmospheric climate. The results indicate that the sensible heat-loss effect of leads in winter is more important than the radiative heat-gain effect in summer. For variations in lead fraction roughly commensurate with the uncertainty in observed values, the largest response is found in the Northern Hemisphere winter. That is, for an increase in lead fraction from about $1 \%$ to about $5 \%$, a $5 \mathrm{~K}$ increase in surface-air temperature over the ice-covered area in March in the Arctic, versus only $1 \mathrm{~K}$ in September in the Antarctic, is found. The lower sensitivity in the Antarctic is due to the higher lead fraction in the standard case (because the ice is typically thinner than in the Arctic). This implies a proportionally smaller increase in lead fraction in the high-lead experiment. We can compare the results obtained here with those obtained earlier for the Southern Hemisphere by Simmonds and Budd (1991) (bearing in mind that the present model simulates the entire annual cycle, and we examined the sensitivity at the times of minimum and maximum extent, namely March and September, whereas the model of Simmonds and Budd (1991), was run in perpetual July mode). Our results for increasing lead fraction are similar to those of Simmonds and Budd (1991) who found a $1.2 \mathrm{~K}$ increase in surface-air temperature over Antarctic sea ice and a generally insignificant change in sea-level pressure for an increase in lead fraction from $0 \%$ to $5 \%$.

It must be stressed that the experiments consider the direct effect of leads on atmospheric climate - they do not consider the full range of feedbacks between the atmosphere and ice cover. So, although the results indicate that plausible variations in lead fraction affect only local ocean-atmosphere heat exchange and have no significant effect on atmospheric circulation, this would not necessarily be the case in a fully coupled model, in which ice extent and ocean temperature evolve freely. Indeed, the results of Vavrus (1995) indicate that these feedbacks are important and they will be investigated in future work with coupled atmosphere slab-ocean versions of the AGCM.

\section{ACKNOWLEDGEMENTS}

We are grateful to the following people for conducting and making available the 40 year standard simulation: G. Boer, R. Hourston, S. Lambert, M. Lazare and F. Zwiers. We also thank G. Boer, J. Fyfe, S. Kharin, J. Maslanik, S. Vavrus and F. Zwiers for helpful advice and/or review comments.

\section{REFERENCES}

Boer, G. J., N. A. McFarlane and M. Lazare. 1992. Greenhouse gas-induced climate change simulated with the CCC second-generation general circulation model. f. Climate, 5 10), 1045-1077.

Cavalieri, D. J. 1992. The validation of geophysical products using multisensor data. In Carsey, F. D., ed. Microwave remote sensing of sea ice. Washington, DC, American Geophysical Union, 233-242. Geophysical Monograph Series 68.

Flato, G. M. and W. D. Hibler, III. 1995. Ridging and strength in modeling the thickness distribution of Arctic sea ice. 7 . Geophys. Res., 100 (C9). $18,611-18,626$.

Gates, W. L. 1992. AMIP: the Atmospheric Model Intercomparison Project. Bull. Am. Meteorol. Soc., 73 (12), 1962-1970.

Gloersen, P., W. J. Campbell, D. J. Cavalieri, J. C. Comiso, C. L. Parkinson and H.J. Zwally. 1992. Arctic and Antarctic sea ice, 1978-1987: satellite passive-microwave observations and analysis. Washington, DC, National Aeronautics and Space Administration. (NASA-SP-511.

Herman, G. F. and W.T. Johnson. 1978. The sensitivity of the general circulation to Arctic sea ice boundaries: a numerical experiment. Mon. Weather Rev., 106 (12), 1649-1664.

Ledley, T. S. 1988. A coupled energy balance climate sea ice model: impact of sea ice and leads on climate. J. Geophys. Res., 93 D12, 15,919-15,932.

Maykut, G. A. 1978. Energy exchange over young sea ice in the central Arctic. J. Geoplyys. Res., 83 (C7), 3646-3658.

McFarlane, N. A., G. J. Boer, J. -P. Blanchet and M. Lazare. 1992. The Canadian Climate Centre second-generation general circulation model and its equilibrium climate. J. Climate, 5 (10), 1013-1044.

Mitchell, J. F. B. and C. A. Senior. 1989. The Antarctic winter; simulations with climatological and reduced sea-ice extents. Q. F. R. Meteorol. Soc., 115 (486), 225246.

Raymo, M. E., D. Rind and W. F. Ruddiman. 1990. Climatic effects of reduced Arctic sea ice limits in the GISS II general circulation model. Paleoceanograph); 5 (3), 367-382.

Rind, D., R. Healy, C. Parkinson and D. Martinson. 1995. The role of sea ice in $2 \mathrm{x} \mathrm{CO}_{2}$ climate model sensitivity. Part I: The total influence of seaice thickness and extent. 7. Climate, 8 (3), 449-463.

Royer, J. F., S. Planton and M. Déqué. 1990. A sensitivity experiment for the removal of Arctic sea ice with the French spectral general circulation model. Climate Dyn., 5(1), 1-17.

Simmonds, I. and W. F. Budd. 1991. Sensitivity of the Southern Hemisphere circulation to leads in the Antarctic pack ice. Q. J. R. Meteorol. Soc., $117(501), 1003-1024$.

Vavrus, S. J. 1995. The sensitivity of the Arctic climate to leads in a coupled atmosphere-mixed-layer ocean model. f. Climate, 8 2), 158-171.

Zwiers, F.J. In press. Interannual variability and predictability in an ensemble of AMIP climate simulations conducted with the CCC GCM2. Climate Dyn. 